\title{
Saccular Dysfunction in Low-Frequency Age-Related \\ Sensorineural Hearing Loss
}

\author{
Emami SF1 and Abdoli $\mathrm{A}^{2 *}$ \\ ${ }^{1}$ Department of Audiology, faculty of rehabilitation, Hamadan University of Medical \\ Sciences, Hamadan, Iran \\ ${ }^{2}$ Department of Neuro- Surgery, faculty of physician, Hamadan University of Medical \\ Sciences, Hamadan, Iran
}

\section{Research Article \\ Volume 2 Issue 1}

Received Date: February 07, 2017

Published Date: April 10, 2017

DOI: $10.23880 /$ ooaj-16000151

*Corresponding author: Abdoli A, Department of Neuro-Surgery, Faculty of Physician, Hamadan University of Medical Sciences, Hamadan, Iran, E-mail: A.abdoli@umsha.ac.ir, aliabdoli999@yahoo.com

\section{Abstract}

Objective: To estimate the relationship between saccular dysfunction and low frequency age-related sensorineural hearing loss (a-SNHL).

Methods: In this case-control study, sixty old men volunteers evaluated met inclusion criteria. They presented to the audiology department of Hamadan University of medical sciences (Hamadan, Iran). After history taking, all of audiological tests done on same.

Results: The comparison of the mean latencies and the mean peak-to-peak amplitudes of the cVEMPs in two groups had significant differences $(\mathrm{P}<0.05)$. The control group with mild high tone hearing loss (normal pure tone thresholds in low to mid frequencies) had normal cVEMPs findings. The case subjects with flat audiogram had abnormal cVEMPs results.

Conclusion: Sound sensitivity of the saccule tended to decline when a-SNHL in low frequencies increased. The weakening in cochlear and saccular function of aging may reveal the mechanical failure of both structures, which include the insufficiency of physical properties of the cochlea and the otolithic organ.

Keywords: Saccule; Cervical Vestibular Evoked Myogenic Potentials; Sensorineural Hearing Loss

Abbreviations: cVEMPs: Cervical Vestibular Evoked Myogenic Potentials; a-SNHL: Age-Related Sensorineural Hearing Loss

\section{Introduction}

Presbycusis is the term traditionally used when referring to hearing loss in older people, with disturbances in peripheral and central auditory pathways. The modifiable risk factors in a-SNHL include noise, smoking, ototoxicity, and multiple health comorbidities including cochlear blood supply (CVD), cardiovascular disease, diabetes, and cognitive decline [1]. It has variable forms of clinical expression (sensory, neural, strial, mechanical, mixed, intermediate) and is not necessarily represented by a single pattern [1,2]. The sensory presbycusis appears to have more to do with long-term exposure to environmental toxicities such as noise, than with age, per se. It is higher in men than women and audiograms has high-frequency hearing loss [1,2]. The 


\section{Otolaryngology Open Access Journal}

neural presbycusis is degeneration of the population of neural units and may be associated with involving all three turns of the cochlea. It may explain deficits in auditory processing, intensity and temporal coding with high-frequency loss $[1,2]$. The strial presbycusis is the most common feature a-SNHL. There is a direct correlation between strial degeneration and evoked potential voltage. Low-frequency hearing loss is typical of persons with strial presbycusis, which appears to be more pronounced in women $[1,2]$.

The mechanical presbycusis is associated with changes in the physical properties of the cochlea such as loss of elasticity of the basilar membrane, which affects its mechanical response. Cochlear conductive presbycusis may merely be an extreme case of metabolic presbycusis. A very low evoked potential is associated with a mild, flat audiogram with hearing loss greater in the low frequencies $[1,2]$. The mixed presbycusis is characterized by the involvement of two or more of the four classic types of presbycusis [1]. The intermediate presbycusis is characterized by the presence of submicroscopic alterations in structures of the cochlea that control cell metabolism, a decrease in the number of synapses on hair cells, and chemical changes in endolymph. Audiograms are primarily flat or mildly descending, without consistent or distinct pathologic correlates [1].

There is actually the possibility of the saccular damage in sensory presbycusis. Recent investigations in older adults have described that a-SNHL may be associated with vestibular dysfunction and high-frequency hearing loss was associated with reduced saccular function, yet not with utricular or semicircular canal function. This concomitant decline, may reflect the common embryologic origin of both structures, which comprise the pars inferior of the labyrinth [3,4]. Yet, it is not certainly clear, is there or not the concomitant decline in saccular function and low frequency a-SNHL? Hence, the aim of the present study was to estimate the relationship between the saccular dysfunction and low frequency age related sensorineural hearing loss (a-SNHL).

\section{Ethical Considerations}

This study was on human subjects, so to minimize harms and risks and maximize benefits and respect human dignity, privacy, autonomy, immunity, safety, respectability, and satisfaction, we took human precautions with our groups and strived to distribute the benefits and burdens of research fairly.

\section{Material and Methods}

In this case- control study, which was approved by the Hamadan university of medical sciences ethics committee (grant number $=870464207$ ), sixty old men volunteers (mean age $64.2 \pm 4.3$ years; range $=59-76$ years) met inclusion criteria. They presented to the audiology department of Hamadan university of medical sciences (Hamadan, Iran) from September through december 2015 (total $=120$ ears). After history taking, all of the tests done on same day and performed bilaterally by our audiologists. All the participants underwent auditory and vestibular test batteries using audiometry (Madsen, OB822) impedance acousticmetry (Maico, MI. 34), cVEMPs (Labat Epic-plus) and Videonystagmography (Synapsis, VNG advanced), which was conducted to eliminate the possibility of any additional vestibular pathology. The thin-sliced CT scans of the temporal bone were performed on of the subjects (to reveal normal middle and inner ear anatomy).

The investigation included subjects with symmetrical pattern of mild a-SNHL $\{25<$ degree $<40 \mathrm{~dB}$ HL [5] $\}$, normal otoscopic, videonystagmographic, head, neck exams and CT scans exams. The participants also should be able to produce a cVEMPs at $500 \mathrm{~Hz}$. The research excluded persons with history of ear infections and middle ear diseases and ear surgeries, signs and/or symptoms of superior semicircular canal dehiscence during clinical and audiological examinations (fistula sign and/or Tullio phenomenon), complaints of dizziness, neurologic disease, known disease affecting the cervical vertebrae or spinal cord. During audiological assessments, the air-conduction thresholds were obtained from each person over the frequency range of 250-500$750-1000-2000-4000-6000-8000 \mathrm{~Hz}$ and boneconduction thresholds were conducted at 250-500-7501000-2000- $4000 \mathrm{~Hz}$ [5]. The middle ear pressure admittance measurements system was calibrated using a four-chamber coupler (model: CC4-V) in accordance with manufacture guidelines. Middle-ear pressure between the limits of \pm 50 dapa was evaluated [6].

For the cVEMPs, patients were placed in the supine position on a gurney within a sound-treated room. They instructed to turn and hold their heads as far as possible toward the side contra lateral to the stimulated ear (thereby activating the ipsilateral sternocleidomastoid muscle). At that point, the overall electromyogenic activity set as the reference level of the tonic contraction (usually $100-400 \mu \mathrm{V}$ ). Patients were asked to maintain contraction at this level throughout the test session (approximately $40 \mathrm{~s}$ ). 


\section{Otolaryngology Open Access Journal}

The active electrode was placed over the middle portion of the ipsilateral muscle body. The reference and the ground electrodes were placed over the upper sternum and on the midline forehead, respectively. Impedance was less than $10 \mathrm{k} \Omega$.

Auditory stimuli consisted of tone burst through Etymotic ER-3A insert earphones $(500 \mathrm{~Hz}, 125 \mathrm{~dB}$ peak $\mathrm{SPL}$, rise $/$ fall time $=1 \mathrm{~ms}$, plateau $=2 \mathrm{~ms}$ ), presented to the ear ipsilateral to the contracted muscle, band pass filtered $(20 \mathrm{~Hz}$ to $2 \mathrm{kHz}$ ), and a grand-average of the 200 responses was recorded [7]. All responses were repeated and the two runs were grand averaged. A present cVEMPs was defined as an initial positive peak followed by a subsequent negative peak. The norming process of the cVEMPs included 20 healthy individuals in the age range of 18-26 years (10 females and 10 males, mean age 23 years) with no history or complaint of vestibular, otological or neurological problems.

\section{Statistical Analyses}

Descriptive statistical analysis was used to obtain mean and standard deviation of the cVEMPs, (KolmogorovSmirnov test for evaluation of normal test distribution, Independent t-test to compare findings among two groups). P-value of $<0.05$ was considered to indicate statistical significance.

\section{Results}

On norming process of the cVEMPs, the latencies and the peak to peak amplitudes longer than the calculated upper limit $(\mathrm{p} 13=16.43, \mathrm{n} 23=24.93 \mathrm{~ms}$ and $\mathrm{p} 13-\mathrm{n} 23=$ $109.95 \mu \mathrm{v}$ ) were interpreted as abnormal. Comparison of the mean latencies (p13, n23) and peak to peak amplitudes (p13-n23) of cVEMPs across stimulus frequencies are visitable in (Table 1). Dependence of cVEMPs findings, the persons divided to two groups. The subjects with normal (control $=\mathrm{n}=30$ ) and the others with abnormal cVEMPs ( case $=\mathrm{n}=30$ ).

The statistical analysis of independent t-test showed that comparison of the mean latencies and mean peak-topeak amplitudes of the cVEMPs in the control group in compared to the case group had significant differences. The control group with normal cVEMPs had normal auditory sensitivity (hearing thresholds $<16 \mathrm{~dB} \mathrm{HL}$ ) in low to mid frequencies (250-500-750-1000 HZ) and mild high tone a-SNHL (2000-4000-6000-8000 HZ). The case subjects with abnormal cVEMPs had mild a-SNHL in low, mid and high frequencies (flat audiogram).

\begin{tabular}{|c|c|c|c|c|c|c|}
\hline \multirow{2}{*}{ Subject } & \multicolumn{3}{|c|}{ Right } & \multicolumn{3}{|c|}{ Left } \\
\hline & Lp13 (ms) & Ln23 (ms) & Ap13-n23 $(\mu v)$ & Lp13 (ms) & Ln23(ms) & Ap13-n23 ( $\mu v)$ \\
\hline $\begin{array}{l}\text { Thirty old men } \\
\text { volunteers with } \\
\text { flat audiogram } \\
\text { (case group) }\end{array}$ & $\begin{array}{l}17.48 \\
(7.11)\end{array}$ & $25.08(9.5)$ & $73.36(41.48)$ & $18.36(5.79)$ & $26.28(3.5)$ & $69.98(23.43)$ \\
\hline $\begin{array}{l}\text { Thirty old men } \\
\text { volunteers with } \\
\text { mild high tone } \\
\text { hearing loss } \\
\text { (control group) }\end{array}$ & $\begin{array}{l}15.28 \\
(0.38)\end{array}$ & $24.12(2.65)$ & 106.77 (53.91) & $14.12(4.12)$ & $23.56(8.63)$ & 101.79 (58.14) \\
\hline t-test & 5.15 & 2.75 & 3.45 & 4.66 & 2.74 & 2.35 \\
\hline $\mathrm{PV}$ & 0.001 & 0.005 & 0.02 & 0 & 0.004 & 0.03 \\
\hline
\end{tabular}

P-value of $<0.05$ was considered to be statistically significance.

Table 1: Comparison of the mean latencies, peak to peak amplitudes of cervical vestibular evoked myogenic potentials (cVEMPs) in thirty old men volunteers with flat audiogram (case group) and in thirty old men volunteers with mild high tone hearing loss (control group).

\section{Discussion}

Our findings confirm associated degeneration in cochlear and saccular sensitivity to low frequency sounds related to aging. Since, the range of saccular sensitivity to sound lies in low frequencies (the frequencies between $50-800 \mathrm{~Hz}$ above $90 \mathrm{~dB}$ SPL evoke saccular afferents [7]).
So, our case groups who have a low frequency hearing loss /flat hearing loss had a discrepancy in the cVEMPs findings compared to their control group. Then, in our case group with flat audiogram and abnormal cVEMPs findings, there is the probability of mechanical presbycusis, which is associated with changes in the physical properties of the cochlea and the saccule [2]. Indeed, the acoustic sensitivity of the saccule has been 


\section{Otolaryngology Open Access Journal}

attributed to the elastic and inertial properties of the end organs, the mechanical resonance of individual stereocilia, and/or the electrical tuning of the hair cells [8]. The prolonged P13 and N23 latencies and the reduced of the amplitudes observed in the case adults with normal hearing in low and mid frequencies and high tone a-SNHL proposed a dual sensory losses, which suggest that hearing damage in the elderly may be comorbidity by saccular discrepancy, without any potential affecting aspects for instability, unsteadiness and daily living activities [1]. According to a recent report paper, in normal hearing persons and during exposure to lowfrequency intonation of human's voice, the risk of saccular damage is susceptible [9].This is likely a result from the difference in tuning between the hair cells of the cochlea and the saccule. Cochlear hair cells are tuned to respond to frequencies between 20 and $20000 \mathrm{~Hz}$ [10], while saccular hair cells respond to intense air -conducted sound lower than $2000 \mathrm{~Hz}$ [11].

A number of investigators have recently explored the air and bone conducted acoustic activation of the saccule among human the best frequencies did not exceed 1000 $\mathrm{Hz}$ to sound and $500 \mathrm{~Hz}$ to vibration [11, 12]. They reported conservational sounds (voice pitch in speaking, singing, crowd actions, vocalisations and musicalnoises) can stimulate the saccule [13]. The recent articles show that acoustical activation of the saccule in human enhanced temporal fine arrangement signals of the sound and has very important starring role in recognition of harmonic pitch data to separate the message and maskers, which are essential for audible function in noise [14]. The latest reports discuss about a novel finding, which confirms saccular projection activations make the cues in human brainstem to cortex and can possibly contribute to auditory processing [13-16].

Previous studies have focused on the possibility that saccule has auditory sensitivity in human and in the clamor environments may contribute to the hearing of low frequency high-intensity sounds. Indeed, the saccule has a compensatory role for the hearing of aloud low frequencies $(90 \mathrm{~dB} \mathrm{spl}<)$ and allows to phonemic selfregulation [12-16]. More probability of this sacculocochlear comorbidity in elderly is that reduced output from the impaired sensory systems, due in part to a-SNHL changes, decreases the value of the input to the central auditory-vestibular system and eventually the communication challenges concomitant with age related hearing loss [9], it may well be that impaired hearing statuses more necessity on consideration sharing, thus, making mobility further of a challenge. Then results show the function of the saccule tended to decline as a-SNHL in low frequencies increased. The parallel deterioration in cochlear and saccular function related to low frequency loss may reveal the common mechanical decline of both structures, which include the impairment of physical properties of the cochlea and the otolithic organ.

\section{Conclusion}

The results of this investigation have shown that a range of frequencies evoke the largest cVEMPs. The best frequency for evoking a cVEMPs, on average, increases for older adult patients. Accordingly, for older patients 500 $\mathrm{Hz}$ may not be the ideal frequency to elicit cVEMPs. In fact, for some older subjects in this investigation the cVEMPs was only present in response to tone-burst stimuli of $750 \mathrm{~Hz}$ and $1000 \mathrm{~Hz}$. These changes may represent the accumulated effects of age on the electrical resonance of the hair cells, or, age-related changes in the mechanical properties of the otolith end organs. In cases where the cVEMPs response is absent at $500 \mathrm{~Hz}$ we recommend that attempts be made to evoke the cVEMPs with a tone burst of $750 \mathrm{~Hz}$ or $1000 \mathrm{~Hz}$.

\section{Acknowledgment}

Authors are grateful for the support of the Hamadan University of medical sciences ethics committee.

\section{References}

1. Weinstein BE (2015) Hearing Loss in the Elderly: A New Look at an Old Problem. In: Katz J, et al. (Eds.), Hand Book of Clinical Audiology, $7^{\text {th }}$ (Edn.), New York: Lippincott Williams \& Wilkins, pp: 631- 646.

2. Tremblay KL, Burkard RF (2007) The Aging Auditory System: Confounding Effects of Hearing Loss on AEPs. In: Burkard RF (Eds.), Auditory Evoked Potentials Basic Principles and Clinical Application, Baltimore Lippincott Williams \& Wilkins, pp: 403-427.

3. Zuniga MG, Dinkes RE, Davalos-Bichara M, Carey JP, Schubert PT, et al. (2012) Association between Hearing Loss and Saccular Dysfunction in Older Individuals. Otol Neurotol 33(9): 1586-1592.

4. Agrawal Y, Carey JP, Della Santina CC, Schubert MC, Minor LB (2009) Disorders of balance and vestibular function in US adults: data from the National Health and Nutrition Examination Survey, 2001-2004. Arch Intern Med 169(10): 938-944.

5. Harrell RW (2002) Pure tone evaluation. In: Katz J, et al. (Eds.), Hand Book of Clinical Audiology, $5^{\text {th }}$ (Edn), New York: Lippincott Williams \& Wilkins pp: 71-88. 


\section{Otolaryngology Open Access Journal}

6. Clarck JL, Roesser R (2007) Middle ear measures. In: Roesser R, et al. (Eds.), Audiology Diagnosis, 2nd (Edn), New York: Thieme Medical Publisher pp: 387.

7. Hall JW (2007) Electrically evoked and myogenic responses. In: Hall JW, et al. (Eds.), New Handbook of Auditory Evoked Responses, Boston, Pearson Education, Inc pp: 602-613.

8. Emami SF (2015) The effect of loud human's voice on saccular function. Journal of International Research in Medical and Pharmaceutical Sciences 7(4): 153-158.

9. Piker EG, Jacobson GP, Burkard RF, McCaslin DL, Hood LJ (2013) Effects of Age on the Tuning of the cVEMP and oVEMP. Ear Hear 34(6): 65-73.

10. Crawford AC, Fettiplace R (1981) An electrical tuning mechanism in turtle cochlear hair cells. J Physiol 312: 377-412.

11. Murofushi Tkk (2009) Sound sensitivity of the vestibular end-organs and sound-evoked vestibule collic reflexes in mammals. In: Murofushi TKK \& Kaga $\mathrm{K}$ Issues in Vestibular Evoked Myogenic Potential, Japan, Nikkei Printing Inc, Springer Press, pp: 20-25.
12. Sheykholeslami K, Habiby KM, Kaga K (2001) Frequency sensitivity range of the saccule to boneconducted stimuli measured by vestibular evoked myogenic potentials. Hear Res 160(1-2): 58-62.

13. Emami SF (2013) Is all human hearing cochlear? The Scientific World Journal.

14. Emami SF, Gohary N (2014) The vestibular-auditory interaction for auditory brainstem response to low frequencies. ISRN Otolaryngology.

15. Todd NPM, Paillard AC, Kluk K, Whittle E, Colebatch JG (2014) Vestibular receptors contribute to cortical auditory evoked potentials. Hear Res 309: 63-74.

16. Emami SF, Daneshi A (2012) Vestibular Hearing and neural synchronization. ISRN Otolaryngology. 